\title{
THE EFFECT OF AGEING UPON PHYSIOLOGICAL TREMOR
}

\author{
BY \\ JOHN MARSHALL \\ From the Academic Unit, Institute of Neurology, and National Hospitals for Nervous Diseases, Queen Square, London
}

It is a matter of common observation that the standard of motor performance declines with advancing years. There are several factors which may be associated with this. The conduction velocity in human peripheral motor nerve fibres has been shown to decrease by about $15 \%$ between the third and ninth decades (Wagman and Lesse, 1952; Norris, Stock, and Wagman, 1953). On the sensory side, the perception of vibration applied to the lower limbs is impaired in an increasing proportion of apparently normal people after the age of 50 years (Pearson, 1928; Cosh, 1953), and ischaemic and post-ischaemic paraesthesiae are likewise experienced less constantly (Poole, 1956). Reflex activity is also impaired more than can be accounted for by the changes in the efferent and afferent nerves. For example, Magladery, Teasdall, and Norris (1958) have shown that the latency of the flexor plantar response and of the superficial abdominal reflexes is greatly prolonged in old people. Central factors may also be involved, the reaction time, as one example, being demonstrably prolonged in older age groups (Welford, 1958).

Muscular movement in normal young adults is associated with a rhythmic tremor with a frequency of 10 cycles per second (c/s) (Marshall and Walsh, 1956; Halliday and Redfearn, 1956). In children, however, the tremor is slower, having a frequency of only $6 \mathrm{c} / \mathrm{s}$ (Marshall, 1959). This lower frequency in early life, and the knowledge that other nervous functions are affected by both maturation and senescence, made it of interest to study physiological tremor as age advances, first to define further the processes involved in the decline of motor performance, and secondly, to discover more about the nature of physiological tremor.

\section{Materials and Methods}

The method used to record the tremor was that described by Marshall and Walsh (1956). The patient held in his hand an accelerometer, double diode valve (Mullard DDR 100), the anodes of which are deflected by acceleration in one plane. The output from the valve upsets the balance of a bridge circuit, which was in turn fed through an Ediswan electroencephalographic amplifier to an ink writer.

The patient held the valve in the pronated hand with the upper limb fully outstretched and unsupported, so that the tremor recorded was that imparted by the whole of the upper limb. A mark on the valve cover ensured that the anodes were always held in the same plane. The recording was made and the age of the patient noted.

Subsequently, the frequency of the tremor was measured by laying a transparent cursor, ruled off in seconds, over the tracing and counting the number of waves in a second. Several examples were measured, and at the time of making the measurement the observer did not know the age of the subject.

\section{Results}

The tremor was recorded in 347 subjects in th $\frac{+}{8}$ age range 20 to 96 years inclusive. There were 165 T males and 182 females; the number of subjects is each quinquennium is given in Fig. 1.

The subjects comprised persons working in the hospital, patients without obvious neurologics disease in a geriatric unit, and people living in a locat authority institution. There was no difference in the recordings obtained from each of these groups.

The frequency of the tremor of each subject is plotted in relation to age in Fig. 1. This shows that between the ages of 20 and 40 years the frequency of the tremor is around 9 to $11 \mathrm{c} / \mathrm{s}$ with no evidence of a decline in frequency during this period of years. From the age of $\mathbf{4 0}$ onwards, however, there is a steady decline in frequency, a decline which affects the whole of the sample population and is not confined to one particular group of subjects. In Fig. 2 the mean tremor frequency has been plotted against the mean age of the subject in quinquennial periods. This indicates that the mean frequency declines from just over $9 \mathrm{c} / \mathrm{s}$ at the age of 40 years to $6.5 \mathrm{c} / \mathrm{s}$ in the 70-74 age group and remains about this level between 70 and 90 years. There were only four subjects in the tenth decade, one aged 91 , one 93 , and two 97 years, all with a tremor frequency of $6 \mathrm{c} / \mathrm{s}$. The observations in these upper age groups are too few to indicate whether the tremor frequency continues to decline after 70 years or whether it stabilizes 


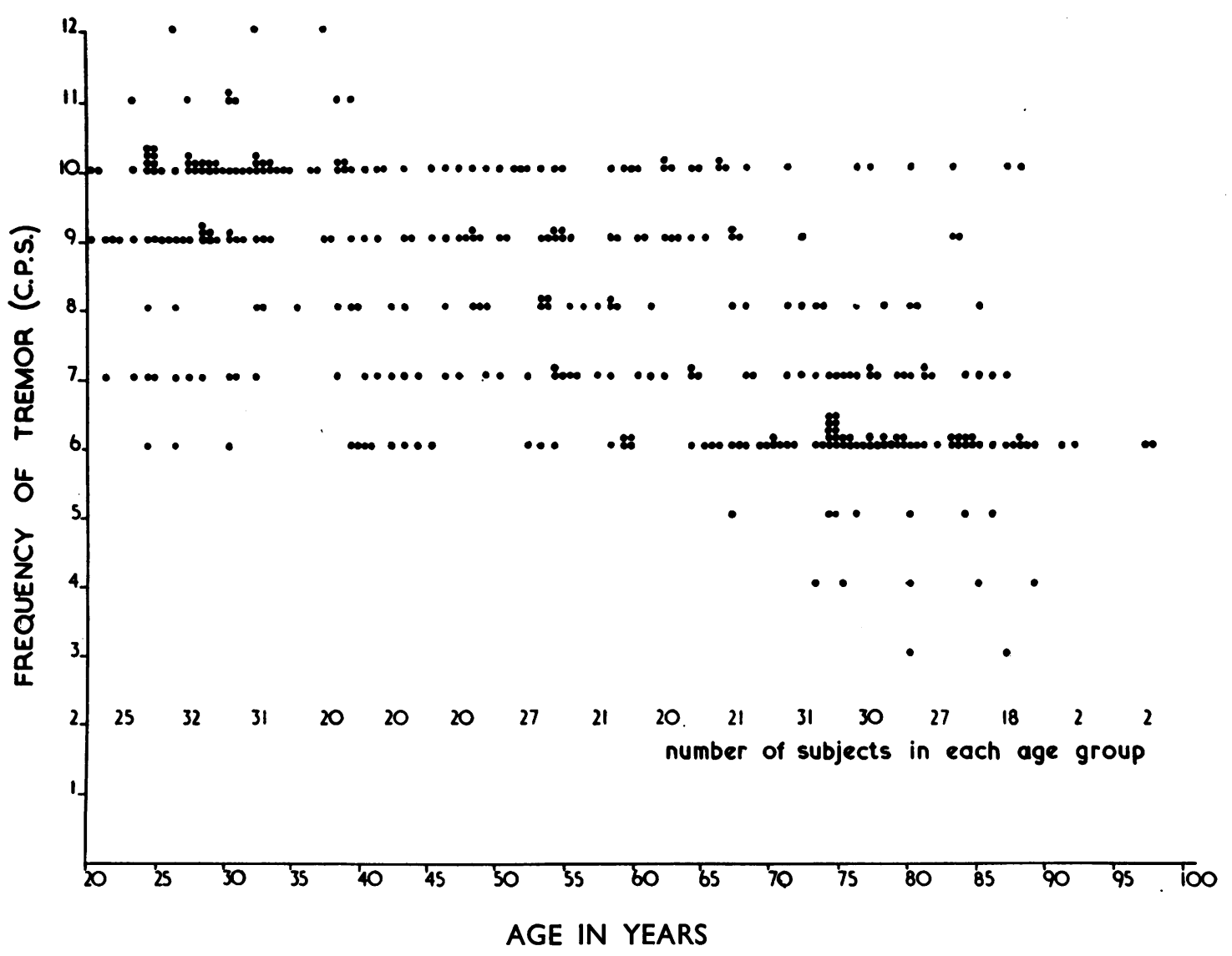

Fig. 1.-Graph showing the number of patients with each tremor frequency at each year of age.

at $6 \mathrm{c} / \mathrm{s}$. Such indication as is provided by the data favours the latter possibility.

A regression line can be fitted to the data for the 40 to 97 year group of the equation $y=10.89-$ $0.053 \mathrm{x}$ where $\mathrm{x}$ is the age in years, and is shown in Fig. 2. The slope of this line differs significantly from that for the 20-39 year group which has the equation $\mathrm{y}=9.014+0.007 x(\mathrm{P}<0.001)$.

\section{Discussion}

These observations have shown that the frequency of physiological tremor, which is about $10 \mathrm{c} / \mathrm{s}$ in early adult life, declines significantly to a frequency of $6 \mathrm{c} / \mathrm{s}$ from the age of 40 years onwards. Though occasional patients had a tremor frequency below $6 \mathrm{c} / \mathrm{s}$, there is a suggestion that the frequency stabilizes at $6 \mathrm{c} / \mathrm{s}$ and does not in general decline further. The decline in frequency affects all subjects, there being no suggestion of the emergence of two groups, one maintaining the $10 \mathrm{c} / \mathrm{s}$ tremor, the other developing a slower tremor. The slower tremor of old age is not, therefore, an abnormality afflicting certain persons, but is the normal accompaniment of advancing years. It must not be confused with the so-called senile tremor, in which the outstanding feature is a greatly increased amplitude. The exact nosological status of senile tremor is not clear, but it appears to be related to essential or familial tremor (Critchley, 1949).

The significance of the slowing of tremor frequency in old age cannot be considered without reference to the mechanism underlying the tremor of young adults. Marshall and Walsh (1956) were of the opinion that it is due to the muscles acting as a low-pass filter, and failing to follow stimulation frequencies higher than about $10 \mathrm{c} / \mathrm{s}$ reaching them from the nerve fibres. On the other hand, Halliday and Redfearn (1958), observing that the tremor frequency was reduced in patients with tabes dorsalis in whom there was clinical evidence of 


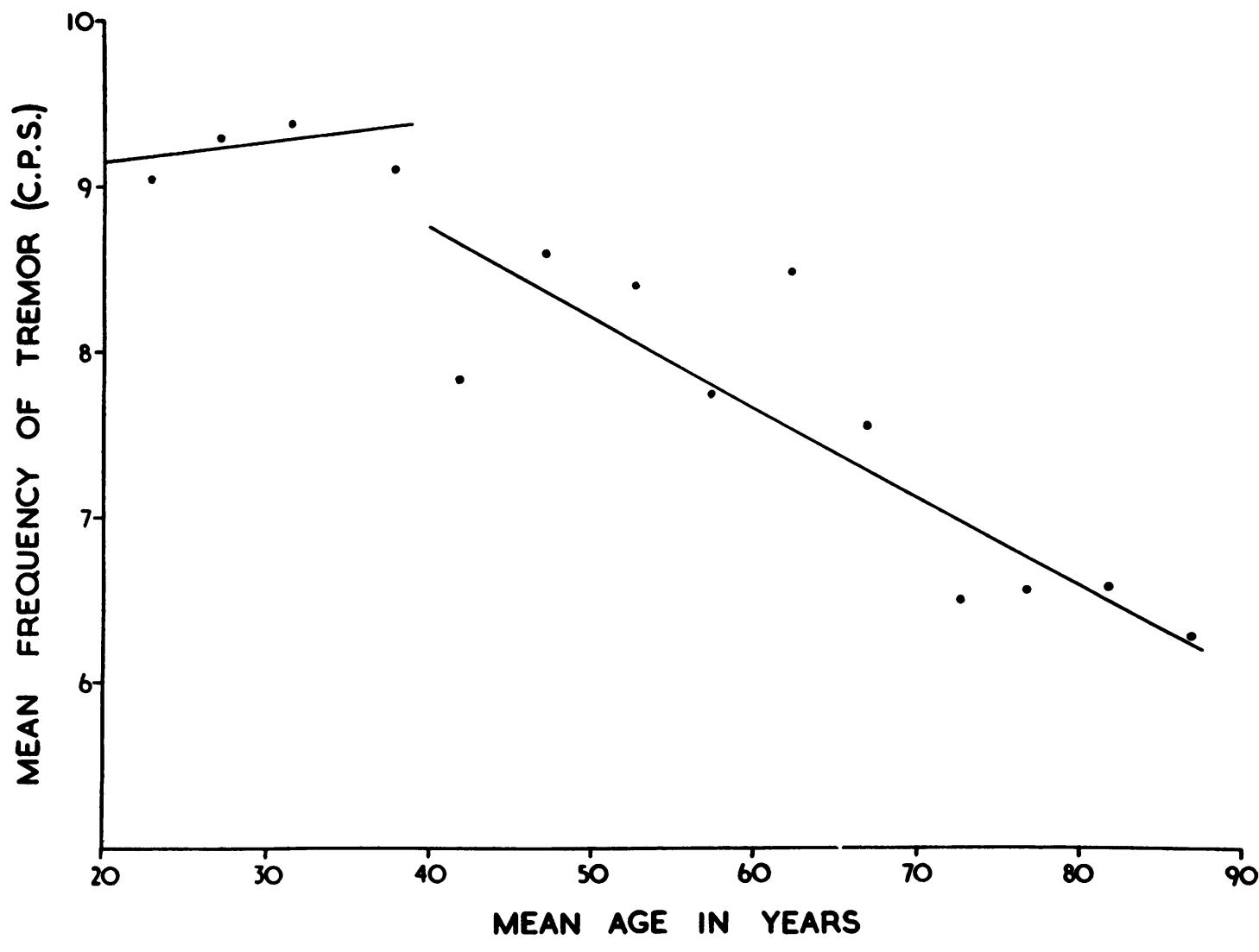

Fig. 2.-Graph showing the mean tremor frequency for each quinquennium with regression lines for the 20-39 and the 40-97 year groups.

damage to afferent nerve fibres, postulated that the normal tremor is due to the oscillation of impulses around the spinal reflex arc. If this latter explanation were the case, the reduced tremor frequency of old age might be attributed to changes in the reflex arc itself. The slowing in the conduction velocity in human motor nerve fibres of some $15 \%$ which has been demonstrated (Norris et al., 1953) is; however, entirely inadequate to account for the reduction of tremor frequency from 10 to $6 \mathrm{c} / \mathrm{s}$, even were it shown that there is a similar reduction in conduction velocity in the afferent limb of the reflex arc.

There is evidence that there is increasing synaptic delay with advancing years, at least in rats (Wayner and Emmers, 1958). This delay was not attributed to changes localized in the synapse, but to a decrease in the excitatory impulses reaching the synapse from other parts of the nervous system. That such influences may operate in man is indicated by the observation of Magladery and Teasdall (1958) and
Teasdall and Magladery (1959) that lesions of the descending motor pathways prolong the latency of the stretch reflexes and of the superficial abdominal reflexes. These influences might also control the frequency of the oscillation in the reflex arc which has been suggested by Halliday and Redfearn (1956) as responsible for the normal tremor accompanying muscular movement. They might normally be absent in childhood, accounting for the lower tremor frequency up to the age of about 9 years (Marshall, 1959), appear during puberty, persist during early adult life, and decline after the age of $\mathbf{4 0}$ years or so. Speculation as to the source of these influences would have to take into account the fact that tremor at a frequency of $10 \mathrm{c} / \mathrm{s}$ accompanies reflex movements of the lower limbs in patients with complete interruption of the spinal cord pathways (Marshall and Walsh, 1956).

The development of the $10 \mathrm{c} / \mathrm{s}$ tremor occurs fairly abruptly at puberty, suggesting the replacement of one controlling influence by another rather 
than the maturation of the same influence. The decline of the tremor frequency in later life is not so abrupt, but neither is senescence so dramatic an event as puberty. The suggestion that the tremor eventually appears to stabilize at a frequency of $6 \mathrm{c} / \mathrm{s}$, the level from which it started in childhood, lends support to the concept of one controlling influence being replaced by another.

\section{Summary}

The tremor of the outstretched hand has been recorded in people between the ages of 20 and 96 years. The frequency declines after the age of 40 years from the $10 \mathrm{c} / \mathrm{s}$ in young adults to $6 \mathrm{c} / \mathrm{s}$. The significance of the observations in relation to the mechanism of physiological tremor is discussed.

I wish to thank Mrs. D. Joyce for the statistical analysis, Mr. J. MacNaughton for technical assistance, and the Central Research Fund of the University of London for a grant towards apparatus.

I also wish to thank Dr. N. Exton Smith and Dr. K. Kropach for allowing me to examine patients under their care.

\section{REFERENCES}

Cosh, J. A. (1953). Clin. Sci., 12, 131.

Critchley, M. (1949). Brain, 72, 113.

Halliday A. M., and Redfearn, J. W. T. (1956), J. Physiol. (Lond.), 134,600 .

(1958). J. Neurol. Neurosurg. Psychiat. 21, 101.

Magladery, J. W., and Teasdall, R. D. (1958). Bull. Johns Hopkins Hosp., 103, 236

,, and Norris, A. H. (1958). J. Geront., 13, 282.

Marshall, J. (1959). J. Neurol. Neurosurg. Psvchiat., 22, 33.

-, and Walsh, E. G. (1956). Jbid., 19, 260 .

Norris, A. H., Stock, N. W., and Wagman, I. H. (1953). J. appl. Physiol., 5, 589 .

Pearson, G. H. J. (1928) Arch Neurol Psychiat (Chicago), 20, 482

Pearson, E. W. (1956). J. Neurol. Neurosurg. Psychiat., 19, 148.

Teasdall, R. D., and Magladery, J. W. (1959). A.M.A. Arch. Neurol. Psychiat., 81, 28.

Wagman, I. H., and Lesse, H. (1952). J. Neurophysiol., 15, 235.

Wayner, M. J., and Emmers, R. (1958). Amer. J. Physiol., 194, 403.

Welford, A. T. (1958). Ageing and Human Skill. Oxford University Press, London.

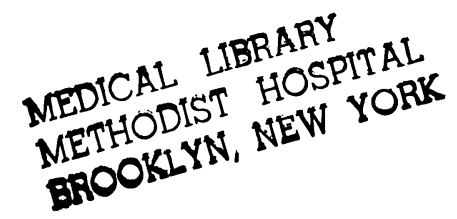

